\title{
Pendidikan Karakter untuk Anak Usia Dini
}

\author{
Slamet Suyanto \\ slametsuyanto@yahoo.com \\ Universitas Negeri Yogyakarta
}

\begin{abstract}
Abstrak
Menumbuhkembangkan nilai-nilai universal dan mengembangkan karakter bangsa sebaiknya dimulai sejak usia dini. Anak usia dini dalam perkembangan yang paling cepat dalam berbagai aspek termasuk aspek agama, moral, sosial, intelektual, dan emosi. Perlakuan pendidikan yang diberikan pada usia dini diyakini akan terpateri kuat di dalam hati dan pikiran anak yang jernih. J ika anak didik dengan baik, diberi contoh yang baik, dan dibiasakan hidup dengan nilai dan karakter yang baik, maka mereka cenderung menjadi orang yang baik yang berhati emas, berpikiran positif, dan berbudi mulia. Persoalannya adalah bagaimana mengembangkan karakter yang baik pada anak usia dini? Apa saja tema dan kegiatan yang yang relevan untuk mengembangkan karakter pada anak usia dini? Bagaimana melakukan asesmen perkembangan karakter pada anak usia dini? Makalah ini menjawab berbagai persoalan tersebut.
\end{abstract}

Kata kunci: Pendidikan Karakter, PAUD

\begin{abstract}
Nurturing universal values and building the national character start better since early years. Young children are in the fastest developing phase of many aspects, including moral, social, intellectual, and emotional. Any given treatment in this phase is considered to be strongly imprinted to their clear heart and mind. If young children are nurtured, having good models of behavior, and accustomed to live with good values and characters, they tend to become good people with a golden heart, mind, and behavior. The problem is how to develop character education in early childhood education? What kinds of values and characters would be appropriate to develop in early years? What kinds of themes and activities are relevant to instill the values and characters? What is the role of teachers, parents, and community in character education for young children? How to assess the development of the characters? This paper addresses those questions to develop character education for young children.
\end{abstract}

Keywords: character education, early childhood education

\section{Pendahuluan}

Pendidikan anak usia dini merupakan investasi bangsa; jika ingin mengembangkan bangsa Indonesia menjadi bangsa dengan nasionalisme, integritas, dan karakter yang kuat maka mulailah sejak anak usia dini. 
Bangsa Indonesia sedang mengalami masa transisi dari masyarakat yang serba terpimpin menjadi masyarakat demokratis. Masa transisi ini ternyata sangat berat, mahal, dan menimbulkan banyak korban. Terhitung sejak orde baru berganti, banyak terjadi demo besar-besaran disertai kerusuhan dan perusakan di berbagai daerah. Tidak jarang hal itu menelan korban jiwa. Ironis, usaha mewujudkan masyarakat yang religius, berperikemanusiaan, demokratis, adil dan sosial justru berakhir dengan kericuhan, kekerasan, dan kerusakan. Perselisihan antar etnis, ras, dan agama, serta antara pemerintah dengan masyarakat sering terjadi. Demikian pula kasus pembunuhan, bunuh diri, dan kriminalitas lainnya menyebabkan 1.4 juta orang terbunuh pada tahun 2001 (Kamanto Soenarto, dkk. 2004).

Kondisi bangsa yang serba terpuruk terbawa oleh siswa ke sekolah. Banyak siswa yang tawuran, terkena narkoba, dan berbuat anarkis. Bahkan, akhir-akhir ini banyak siswa yang bunuh diri karena hal-hal yang tidak begitu penting, seperti diejek teman, tidak bisa membayar SPP, atau tidak lulus UN. Siswa juga kurang termotivasi untuk belajar dengan giat, kurang tekun dan mudah menyerah. Sekolah mengalami kesulitan mendidik siswanya agar menjadi pemelajar yang gigih, mandiri, dan tak kenal lelah. Untuk itu, diperlukan pendidikan yang tidak hanya mengembangkan pengetahuan, tetapi juga pikiran yang tajam dan jernih, perilaku, tutur kata dan sikap yang anggun dan etis, serta memiliki mental baja untuk berhasil dan berprestasi yang semua itu terang-kum di dalam pendidikan karakter.

Pemerintah, melalui Direktorat PSMP telah mengembangkan Grand Desain Pendidikan Karakter (Direktorat PSMP: 2009) yang diharapkan dapat menjadi panduan pendidikan karakter di sekolah. Serangkaian sosialisasi juga telah dilakukan di berbagai sekolah. Namun demikian, pendidikan karakter seperti itu untuk pendidikan anak usia dini belum ada. Padahal penanaman nilai-nilai moral, sosial, intelektual, dan emosional secara terpadu merupakan isu sentral pendidikan anak usia dini. Untuk itu, diperlukan pikiran, wawasan, dan disain pendidikan karakter agar pengembangan karakter dapat dilakukan sejak usia dini.

\section{Konsep Pendidikan Karakter}

Pada tahun 1993, Josephson Institute of Ethics mensponsori pertemuan di Aspen, Colorado, Amerika Serikat untuk mendiskusikan penurunan moral dan cara mengatasinya. Sebanyak dua puluh delapan orang pemimpin dunia merumuskan nilai-nilai universal yang diturunkan dari nilai-nilai kultural, ekonomi, politik, dan agama. Hasil pertemuan itu kemudian dikenal dengan Aspen Declaration on Character Education (DeRoche, 2009). Momentum itu dikenal sebagai kebangkitan kembali pendidikan karakter yang dahulu pernah ada. Pendidikan karakter yang dirumuskan di dalam deklarasi Aspen tersebut di atas adalah sebagai nilai etis dari masyarakat yang demokratis, seperti hormat, bertanggungjawab, dapat dipercaya, adil dan fair, peduli, nilai-nilai kemasyarakatan dan kewarganegaraan. Murphy (1998) meringkasnya sebagai berikut.

\begin{abstract}
"According to the Declaration, effective character education is based on core ethical values rooted in democratic society, in particular, respect, responsibility, trustworthiness, justice and fairness, caring, and civic virtue and citizenship."
\end{abstract}

Konsep pendidikan karakter terus berkembang sejalan dengan pemikiran-pemikiran baru. Cun- 
ningham (2007:5) dari National-Louis University, USA menyatakan bahwa karakter yang diajarkan di sekolah adalah kepanjangan dari karakter, moral atau nilai yang ada dan dihargai di masyarakat, yang dikenal sebagai karakter sosial normatif. Karakter normatif meliputi kejujuran, pantang menyerah, kebersahajaan, kewajaran, dan menja-ga emosi, di mana sekolah berperan sebagai agen moral. Ia menyatakan,

\begin{abstract}
"One way to think about character is to see it as the extent to which a moral agent exemplifies the moral ideas of a society. We can call this socially normative character. Gather together all of those idealshonesty, perseverance, modesty, temperance, whatever-and convert them into behaviors..."
\end{abstract}

Konsep pendidikan karakter berikutnya digagas oleh Thomas Lickona (2005), yang menyatakan bahwa karakter yang baik meliputi memahami, peduli, dan berperilaku berdasarkan nilai-nilai etika dasar. Pendidikan karakter memiliki peran membantu siswa dan komunitas sekolah untuk memahami nilai-nilai yang baik dan berperilaku berdasarkan nilai-nilai tersebut. Ia mengatakan,

\section{"Good character consists of understanding, caring about, and acting upon core ethical values. The task of character education therefore is to help students and all other members of the learning community know "the good," value it, and act upon it."}

Pendidikan karakter bukan sekedar membiasakan anak berperilaku baik, lebih dari itu, yaitu membentuk pikiran, watak, dan perilaku yang baik yang dengan itu anak berhasil. Hal itu sejalan dengan pendapat DeRoche (2009) yang menyatakan bahwa:
"Therefore character education is not about simply acquiring a set of behaviors. It is about developing the habits of mind, heart, and action that enable a person to flourish."

Berdasarkan kutipan-kutipan di atas, karakter diartikan sebagai nilainilai, sikap, dan perilaku yang dapat diterima oleh masyarakat luas. Karakter tersebut meliputi berbagai hal seperti etis, demokratis, hormat, bertanggung jawab, dapat dipercaya, adil dan fair, serta peduli. Sumbersumber karakter antara lain nilai-nilai kemasyarakatan, ideologi negara, dan kewarganegaraan, nilai-nilai budaya bangsa, agama, dan etnik yang diterima oleh masyarakat Indonesia secara luas sehingga tidak menimbulkan konlfik.

\section{Pendidikan Karakter untuk Anak Usia Dini}

Pendidikan karakter untuk usia dini disesuaikan dengan perkembangan moral pada anak. Menurut Piaget (1965), perkembangan moral meliputi tiga tahap, yaitu (1) premoral, (2) moral realism, dan (3) moral relativism. Sementara Kolhberg (Power, Higgins, \& Kohlberg, 1989) menyatakan bahwa perkembangan moral mencakup (1) preconventional, (2) conventional, dan (3) postconventional. Esensi kedua teori tersebut sama, yaitu pada tahap awal anak belum mengenal aturan, moral, etika, dan susila. Kemudian, berkembang menjadi individu yang mengenal aturan, moral, etika, dan susila dan bertindak sesuai aturan tersebut. Pada akhirnya, moral, aturan, etika dan susila ada dalam diri setiap anak di mana perilaku ditentukan oleh pertimbangan moral dalam dirinya bukan oleh aturan atau oleh keberadaan orang lain; meskipun tidak ada orang lain, ia malu melakukan hal-hal yang tidak etis, 
asusila, dan amoral. Jadi, untuk anak Kelompok Bermain dan TK, perkembangan moral anak umumnya pada tahap premoral dan moral realism. Pada tahap ini ada banyak aturan, etika, dan norma yang anak tidak tahu dan anak belum bisa memahaminya. Untuk itu pendidikan karakter di TK baru dalam tahap pengenalan dan pembiasaan berperilaku sesuai norma, etika, dan aturan yang ada.

\section{Karakter untuk Anak Usia Dini}

Karakter apa saja yang perlu dikembangkan dalam diri anak usia dini? Negara memiliki kepentingan dalam menentukan karakter, khususnya yang terkait dengan ideologi, nasionalisme, hukum, dan kewarganegraraan yang dikenal sebagai karakter bangsa. Karakter bangsa ini dikenalkan sejak anak usia dini dengan cara-cara yang sederhana. Misalnya, anak diajak membuat bendera merah putih dari kertas lalu guru bercerita tentang arti bendera negara merah-putih. Di samping itu, anak juga dikenalkan dengan nilainilai yang bersifat universal yang diterima di seluruh masyarakat Indonesia bahkan dunia; seperti hormat, jujur, murah hati, tekun, memiliki integritas, perhatian, toleran, kerjasama, kerja keras, sabar, tanggung jawab, dan dapat dipercaya. Kini pendidikan anak usia dini menghadapi banyak nilai yang diusulkan oleh berbagai pihak agar masuk dalam kurikulum PAUD, seperti aturan lalu lintas, pendidikan anti korupsi, pendidikan kelautan, pendidikan lingkungan hidup, dan pendidikan pembangunan berkelanjutan. Berikut nilai-nilai, moral, dan karakter yang dikem-bangkan dalam pendidikan anak usia dini yang berbeda tiap negara, sekolah, dan masyarakat. Sebagaimana di-uraikan dalam table berikut.
Tabel 1. Sumber Nilai, Nilai, Wujud, dan Tema. 
Jurnal Pendidikan Anak, Volume 1, Edisi 1, J uni 2012

\begin{tabular}{|c|c|c|c|c|}
\hline $\mathrm{NO}$ & SUMBER & $\begin{array}{l}\text { NILAI, MORAL, } \\
\text { KARAKTER }\end{array}$ & WUJ UD & TEMA \\
\hline 1. & $\begin{array}{l}\text { Negara } \\
\text { Pancasila }\end{array}$ & $\begin{array}{l}\text { - Nasionalisme } \\
\text { - Patriotisme } \\
\text { - Belanegara } \\
\text { - Kepahlawanan } \\
\text { - Kemerdekaaan } \\
\text { - Kemanusiaan } \\
\text { - Persatuan } \\
\text { - Keadilan sosial } \\
\text { - Demokrasi } \\
\text { - Dan sebagainya. }\end{array}$ & $\begin{array}{l}\text { 1. Mengenal nama negara, } \\
\text { peta wilayah, kepala } \\
\text { negara } \\
\text { 2. Mengenal simbol-simbol } \\
\text { kenegaraan: bendera, } \\
\text { lambang negara, lagu } \\
\text { nasional. } \\
\text { 3. Mengenal hari } \\
\text { kemerdekaan, hari } \\
\text { pahlawan, hari } \\
\text { kebangkitan nasional, } \\
\text { dsb. } \\
\text { 4. Mengenal } \\
\text { ketatanegraaan: RT, RW, } \\
\text { Kelurahan, dst. } \\
\text { 5. Mengenal ideologi } \\
\text { bangsa, Pancasila } \\
\text { 6. Mengenal suku-suku, } \\
\text { agama, bahasa di } \\
\text { Indonesia }\end{array}$ & $\begin{array}{l}\text { Negaraku } \\
\text { Hari Kemerdekaan } \\
\text { Hari Pahlawan } \\
\text { Pemilu } \\
\text { Hari } \\
\text { Pendidikan } \\
\text { Bumahku } \\
\text { Dll. } \\
\text { Negaraku }\end{array}$ \\
\hline 2. & $\begin{array}{l}\text { Hak azasi } \\
\text { dan nilai-nilai } \\
\text { kemanusiaan }\end{array}$ & $\begin{array}{ll}\text { - } & \text { Hormat } \\
\text { - } & \text { Jujur } \\
\text { - } & \text { Tanggungjawab } \\
\text { - } & \text { Disiplin } \\
\text { - } & \text { Murah hati } \\
\text { - } & \text { Tekun } \\
\text { - } & \text { Integritas } \\
\text { - } & \text { Perhatian } \\
\text { - } & \text { Toleran } \\
\text { - } & \text { Kerjasama } \\
\text { - } & \text { Kerja keras } \\
\text { - } & \text { Sabar } \\
\text { - } & \text { Dapat dipercaya } \\
\text { - } & \text { Bijaksana }\end{array}$ & $\begin{array}{l}\text { 7. Menghormati orangtua, } \\
\text { orang yang lebih tua, } \\
\text { guru, dan teman } \\
\text { 8. Menyapa, member salam } \\
\text { dengan santun } \\
\text { 9. Berkata benar, tidak } \\
\text { bohong } \\
\text { 10. Mengerjakan } \\
\text { dengan baik } \\
\text { 11. Tepat waktu, } \\
\text { 12. Mau menolong teman, } \\
\text { meminjamkan, } \\
\text { 13. Mau bekerjasama, } \\
\text { berkelompok, } \\
\text { 14. Mau antri, bergiliran, } \\
\text { bergantian, } \\
\text { 15. Menepati janji }\end{array}$ & $\begin{array}{l}\text { Keluargaku } \\
\text { Perbuatan baik } \\
\text { Hak dan Kewajiban } \\
\text { Hormat-menghormati } \\
\text { Tolong-menolong } \\
\text { Perbuatan baik } \\
\text { dan lain-lain }\end{array}$ \\
\hline 3. & $\begin{array}{l}\text { Cinta } \\
\text { Kasih sayang }\end{array}$ & $\begin{array}{ll}\text { - } & \text { Empati } \\
\text { - } & \text { Perhatian } \\
\text { - } & \text { Kebaikan } \\
\text { - } & \text { Memberi } \\
\text { - } & \text { Melayani } \\
\text { - } & \text { Pemaaf } \\
\text { - } & \text { Menyayangi }\end{array}$ & $\begin{array}{l}\text { 16. Berbagi perasaan, } \\
\text { 17. Mendengarkan cerita } \\
\text { teman, } \\
\text { 18. Mengenal perbuatan } \\
\text { baik dan buruk } \\
\text { 19. Mau memberi, berbagi } \\
\text { 20. Mau mengerjakan tugas } \\
\text { piket, membersihkan } \\
\text { kelas } \\
\text { 21. Mau memaafkan teman } \\
\text { 22. Menyayangi teman, } \\
\text { saudara }\end{array}$ & $\begin{array}{l}\text { Temanku } \\
\text { Ulang Tahun } \\
\text { Perbuatan baik } \\
\text { Hari Raya } \\
\text { dan lain-lain }\end{array}$ \\
\hline 4. & Masyarakat & $\begin{array}{ll}\text { - } & \text { Hormat } \\
\text { - } & \text { Sopan-santun } \\
\text { - } & \text { Tatakrama } \\
\text { - } & \text { Etika } \\
\text { - } & \text { Kebersamaan } \\
\text { - } & \text { Gotong royong } \\
\text { - } & \text { Antri } \\
\text { - } & \text { Suka menolong } \\
\end{array}$ & $\begin{array}{l}\text { 23. Hormat pada orang lain } \\
\text { 24. Mengenal etika, } \\
\text { tatakrama, sopan santun } \\
\text { 25. Berkata dengan sopan } \\
\text { 26. Mau memberi salam, } \\
\text { menjawab salam } \\
\text { 27. Mau bergotong royong } \\
\text { 28. Mau antri, bergiliran } \\
\text { 29. Mau menolong, }\end{array}$ & $\begin{array}{l}\text { Rumahku } \\
\text { Lingkunganku }\end{array}$ \\
\hline
\end{tabular}




\begin{tabular}{|c|c|c|c|c|}
\hline & & - Sosial & $\begin{array}{ll}\text { 30. } & \text { berdarma } \\
\text { Mau berbagi, } \\
\text { menunjukkan } \\
\text { solidaritas }\end{array}$ & \\
\hline 5. & Agama & $\begin{array}{ll}\text { - } & \text { Keyakinan } \\
\text { - } & \text { Ibadah } \\
\text { - } & \text { Toleransi } \\
\text { - } & \text { Ketaqwaan }\end{array}$ & 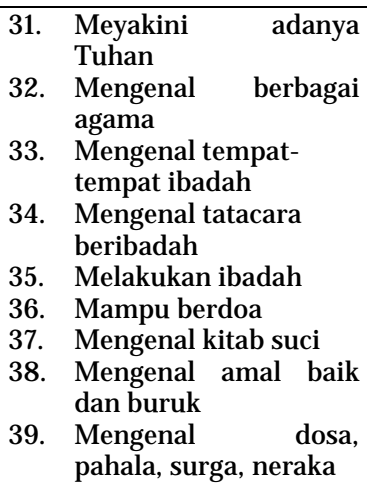 & $\begin{array}{l}\text { Ketuhanan } \\
\text { Hari Raya } \\
\text { Tempat Ibadah } \\
\text { Ibadah } \\
\text { Kitab Suci } \\
\text { Amal Baik } \\
\text { Pahala dan Dosa }\end{array}$ \\
\hline 4. & $\begin{array}{l}\text { Lain-lain: } \\
\text { Kesehatan } \\
\text { Lalu Lintas } \\
\text { Lingkungan hidup } \\
\text { Dll. }\end{array}$ & $\begin{array}{ll}- & \text { Hidup sehat } \\
\text { - } & \text { Tata tertib lalu lintas } \\
\text { - } & \text { Mencintai } \\
& \text { lingkungan }\end{array}$ & 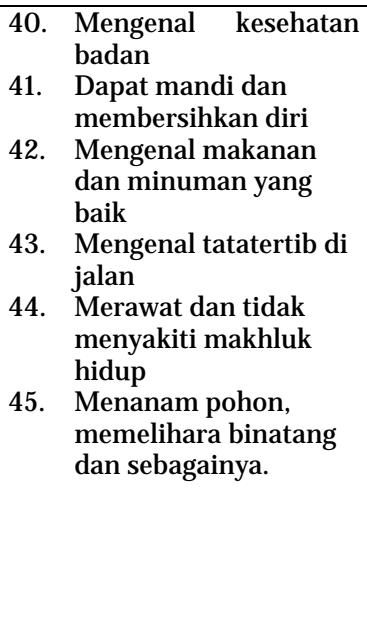 & $\begin{array}{l}\text { Kebutuhanku } \\
\text { Kesehatan } \\
\text { Kebersihan } \\
\text { Makanan dan Minuman } \\
\text { Lalu Lintas } \\
\text { Binatang } \\
\text { Tumbuhan } \\
\text { Dll. }\end{array}$ \\
\hline
\end{tabular}

\section{Pengembangan Karakter dalam PAUD}

Bagaimana mengambangkan karakter pada anak usia dini? Pengembangan karakter untuk anak usia dini dilakukan melalui pembiasaan dan melalui kegiatan inti. Pengenalan melalui pembiasaan dilakukan melalui kegiatan keseharian, seperti mencuci tangan dan berdoa sebelum dan sesudah makan, bercermin dan merias diri, menyisir rambut, dan menata baju, membersihkan dan menata kelas sebelum pulang, berkebun, menanam pohon, dan merawat binatang. Pengenalan melalui kegiatan inti dilakukan melalui kegiatan yang menyenangkan, bermain, simulasi, dan kreasi sesuai capaian perkembangan dan tema. Sebagai contoh, tema "Hari Pahlawan" digunakan untuk mengembangkan sifat kepahlawanan anak-anak. Tema
"Hari Kartini" dapat digunakan untuk mengembangkan sikap emansipasi wanita dan semangat kaum wanita untuk sekolah setinggi mungkin.

Kenyataannya masih banyak guru yang mengajarkan karakter dengan cara berbicara dan mengajak anak berdiskusi. Hamilton (2009) menyindir kebiasaan guru yang banyak bicara dan menyuruh siswa berdiskusi di dalam pendidikan karakter yang tidak cocok untuk anak usia dini. Ia mengatakan:

"Three-to-eight-year-old children will be no more ready to discuss character education after your teacher-talk. Did they learn to walk, to talk, and to feed themselves by discussing it with their parents? No. In spite of that, character education lesson plans 
urge the teacher to discuss - and discuss - and discuss."

Character Education Partnership (CEP) (2010) mengadaptasikan teori Likona tentang implementasi pendidikan karakter yang efektif di sekolah. Ada sebelas prinsip pendidikan karakter yang efektif yaitu sebagai berikut.

1. Sekolah dengan segenap komunitasnya mengembangkan nilai etika dasar dan perilaku yang diyakini sebagai karakter yang baik.

2. Sekolah mendefinisikan karakter secara komprehensif meliputi cara berpikir, bersikap, dan berperilaku.

3. Sekolah menggunakan pendekatan yang komprehensif, mendalam dan proaktif untuk mengembangkan karakter.

4. Sekolah mengembangkan komunitas yang peduli.

5. Sekolah memberi kesempatan kepada siswa untuk mengekspresikan nilai-nilai moral.

6. Sekolah mengembangkan kurikulum yang bermakna dan menantang yang menghormati semua siswa, mengembangkan nilai, dan membantu siswa untuk sukses.

7. Sekolah membantu siswa dalam mengembangkan motivasi diri.

8. Staf sekolah merupakan komunitas belajar etika yang dapat menjadi contoh dan tauladan bagi siswa.

9. Sekolah mengembangkan kepemimpinan bersama dan berbagai pendukung pendidikan karakter.

10. Sekolah melibatkan orangtua dan komunitas sekolah sebagai partner pengembangan karakter.

11. Sekolah secara reguler melakukan asesmen terhadap kultur dan iklim sekolah dan staf dalam pendidikan karakter di mana siswa memanifestasikan karakter yang baik.

Peran guru di dalam pendidikan karakter memiliki peran penting, bukan hanya mengajarkan anak mengenal karakter, tetapi memberi contoh dan membantu anak melakukan karakter dalam bentuk perbuatan yang baik karena anak suka memodelkan apa yang dilakukan gurunya sebagaimana teori learning by modeling dari Albert Bandura. Vardin (2003) mengidentifikasi beberapa peran guru di dalam pendidikan karakter:

1. Memodelkan $\mathrm{k}$ arakter yang baik dan menjelaskannya kepada anak.

2. Membacakan cerita dan mengajak anak memilih nilai-nilai moral yang baik dan yang buruk yang terkandung di dalamnya.

3. Mengajak anak bermain peran antagonis dan memutuskan moral yang baik.

4. Menceritakan cerita tentang legenda, binatang, atau "make believe a story" yang memiliki pesan moral kuat di dalamnya.

5. Mengajak anak berbagi pekerjaan menata dan membersihkan kelas dan membicarakan pentingnya tanggung jawab.

6. Mengunjungi panti asuhan, pati jompo, dan ikut dalam kegiatan kemasyarakatan lainnya dan membahas arti kasih sayang dan kepedulian sosial.

7. Berkebun, menanam, dan menyirami tanaman, serta memberi makan binatang dan membahas arti kasih sayang terhadap makhluk ciptaan Tuhan.

8. Menuliskan daftar karakter, nilai, dan sikap yang sedang dikembangkan dan mengingatkan anak akan hal itu.

9. Membantu, mendorong dan memberi apresiasi siswa untuk berbuat baik sebagai bentuk pembiasaan sehari-hari.

10. Menginformasikan kepada orangtua tentang karakter, nilai dan sikap yang sedang dikembangkan dan meminta bantuan orangtua untuk 
mendorong anak melakukannya di rumah.

\section{Pengenalan Karakter Melalui Pembelajaran Terpadu}

Menurut Fogarty (1991), ada sepuluh model pembelajaran pembelajaran terpadu. Dari sepuluh model tersebut model tematik (webbed model) dan model terpadu (integrated model) tampaknya cocok untuk pengenalan karakter pada anak usia dini. Pada model tematik, unsur karakter masuk di dalam tema-tema yang ada. Misalnya tema Diri Sendiri dapat digunakan untuk membangun karakter yang terkait dengan cara hidup sehat (healthy life styles), hormat dan cinta-kasih terhadap anggota keluarga (respect, love, and care).

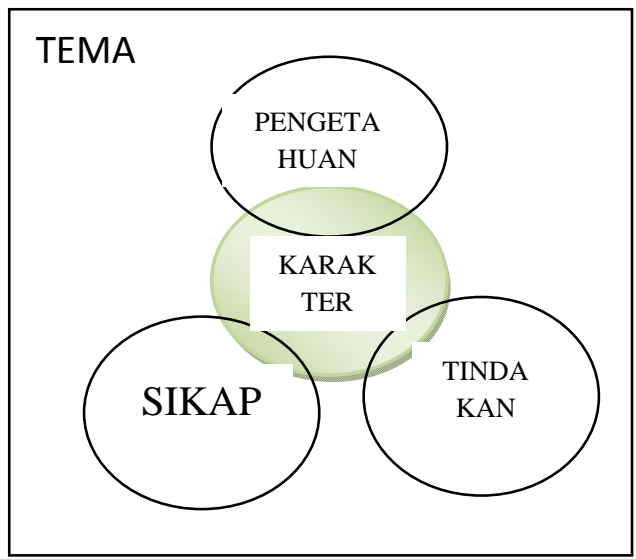

Langkah selanjutnya adalah memasukkan unsur-unsur karakter ke dalam indikator dari tema-tema yang sesuai, memasukkannya ke dalam RKM, dan selanjutnya mencari kegiatan pembelajaran yang sesuai untuk pengembangan karakter dan menuliskannya di dalam RKH.

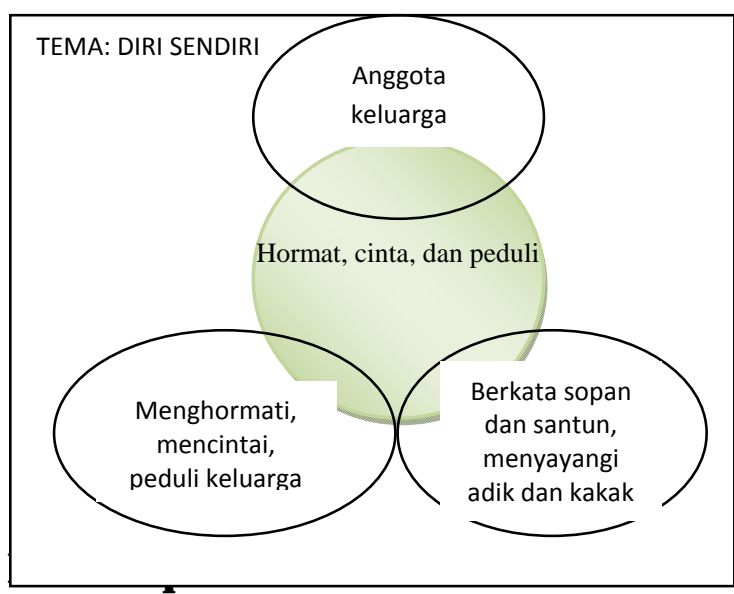

Pendidikan karakter perlu diperkenalkan kepada anak sejak usia dini mengingat perlakuan yang diberikan kepada anak di usia dini akan terpateri kuat di dalam diri anak. Karakter yang diperkenalkan meliputi nilai-nilai universal dan nasionalisme melalui cara-cara sederhana yang mudah dilakukan anak. TK sebaiknya mencanangkan karakter yang dikembangkan di sekolah dan disosialisasikan kepada guru dan orangtua. Guru selanjutnya memodel-kan karakter yang baik agar dapat dicontoh dan ditiru oleh anak-anak. Pembentukan karakter juga dapat dilakukan melalui kegiatan pembiasa-an sehari-hari dan melalui kegiatan inti. Pendidikan karakter di TK sebaiknya dilakukan melalui pembelaj-aran terpadu disatukan dengan tema-tema yang ada. Penilaian karakter hendaknya otentik melalui pengamat-an secara periodik dan terencana.

\section{Daftar Pustaka}

Annan, Koffi. 2003. Global Ethics: "Do We Still Have Universal Values?". 3rd Global Ethic Lecture of the Global Ethic Foundation, given by Kofi Annan Secretary General of the United Nations (1997-2007) Nobel Peace Prize Laureate 
2001, at the University of Tübingen, 12 December 2003.

Berkowitz, Marvin \& Melinda C. Bier. What Works in Character Education: A research-driven guide for educators. http:// www.characterandcitizen ship.org/research/wwceforpract itioners.pdf

Bohlin, Karen, Deborah Farmer, \& Kevin Ryan. 2001. Building character in schools resource guide. San Francisco: J osseyBass.

Character Education Partnership (CEP). 2010. Eleven Principles of Effective Character Education.

http:// www.character.org/ eleve nprinciples

Center for the 4th and 5th Rs (Respect and Responsibility). 2009. What Is Character Education? http:// www2.cortland.edu/cent ers/character/

DeRoche, Edward. 2009. The What, Why, and How of Character Education.

http:// www.csee.org/ products/ $\underline{108}$

Cunningham, Craig A. 2007. Character Education in Public Schools: The Quest for a Suitable Ontology. NationalLouis University. http:// cuip.uchicago.edu/ cac/ pubs.htm

Davis, Michael. 2003. What's Wrong with Character Education? American Journal of Education, volume 110 (2003), http:// www.journals.uc hicago.edu/cgi-bin/ resolve?

Delors, Jacques. et al. 1996. Learning: The Treasure Within. Report to
UNESCO of the International Commission on Education for the Twenty-first century. Australia: UNESCO Publishing.

Educating for Character: How Schools Can Teach Respect and Responsibility. New York: Bantam Book.

Elias, Maurice J. et al. (Eds). 1997. Promoting Social and Emotional Learning: Guidelines for Educator. ASCD, Gaithersburg, Md.: Aspen Publications.45-57

Fogarty, Robin. 1991.The Mindful School: How to Integrate the Curricula. Palatine, Illinois: Skylight Publishing, Inc.

Hamilton, Elizabeth $\quad$ L. 2010. Character Education That Excites Young Children.

http:// ezinearticles.com/

?Character-Education-

That-Excites-Young-

Children!\&id=3849623

Higgins, A. De-Alessandro. 2006. Moral Functioning, moral identity, and moral selfconcepts.

http:// cee.nd.edu/news/ docum ents/HigginsDASummary.pdf

Higgins, A. \& Alessandro (2005). Character Education. http:// en.wikipedia.org/w/ inde x.php?title=Character_educatio n\&oldid $=410411318$

Kamanto Sunarto dkk. (eds) (2001). Multicultural Education in Indonesia and South Asia. Jakarta: Jurnal Antropologi Indonesia. 
Kotler, Philip, Somkid Jatusripitak \& Suvit Maesincee 1997. The Marketing of Nations. New York, NY.: The Free Press.

Lickona, T, Eric Schaps, \& Catherine Lewis. 1994. Eleven principles of effective character education.Washington, DC: Character Education Partnership.

Lickona, T. 2004. Character Matters. New York: Simon and Schuster.(800/988-8081).

Lickona, T. \& Matthew Davidson. 2005. Smart \& good high schools: Integrating excellence and ethics for success in school, work, and beyond. Cortland, NY: The Character Education Partnership.

www.cortland.edu/character/ hi ghschool.

Murphy, M. 1998. Character Education in America's Blue Ribbon Schools. Lancaster, PA: Technomic Publishing.

Madison, James, 2003. Character Education.

http:// www.freedomforum.org/ publications/ first/ findingcomm onground/ B13.CharacterEd.pdf

National Education Association. 1934. Education for Character; Part II: Improving the School Program, NEA Research Bulletin 12(3). Washington: Research Division of the NEA.

Piaget, Jean. 1965. The Moral Judgment of The Child. New York: The Free Press.

Power, F. C.; Higgins, A., \& Kohlberg, L. 1989. Lawrence Kohlberg's
Approach to Moral Education. New York: Columbia University Press.

Richard A Fabes. et al. 1989. Effects of Rewards on Children's Prosocial Motivation: Socialization Study, Developmental Psychology, vol. 25, 1989.

Ronald, S. Thomas. 1991. Assessing Character Education: Paradigms, Problems, and Potentials. Eric Clearing House 65(1), 1991: 51-55

Ryan, K. and Bohlin, K,1999. Building Character in Schools. San Francisco: J ossey-Bass.

Sichel, Betty A. 1988. Moral Education: Character, Community, and Ideals. Philadelphia: Temple University Press.

Stoll, Sharon Kay \& J ennifer M. Beller. 1998. Can character be measured? JOPERD--The Journal of Physical Education, Recreation \& Dance, January 01, 1998. http:// www.accessmylibrary.co $\mathrm{m} /$

Vardin, Patricia. 2008. Enoouraging Good Character in Young Children.

http:// www.edact.com/bl $\mathrm{og} / \mathrm{p}=36$

US Department of Education. 2008. Partnerships in Character Education: State Pilot Projects, 1995- 2001 Lessons Learned. http:// www.ed.gov/programs/c haractered/lessons.html 